\title{
José Pinto Antunes - Novo Titular da Cátedra de Economia Política.
}

Nasceu o Professor José Pinto Antunes no dia 9 de março do ano de 1906, em Lorena, a tradicional cidade do Vale do Paraíba, no Estado de São Paulo.

São seus pais João Batista de Azevedo Antunes e Firmina Pinto Antunes, já falecidos.

Descende, assim, de antigas famílias paulistas, pois seu pai é "Azevedo", da velha estirpe portuguêsa que remonta aos tempos de D. Sebastião; e, do lado materno, a sua ascendência entronca-se nos Buenos de Godoi. É quadrineto do Capitão-Mor Manuel Pereira de Castro, filho, por sua vez, de outro Capitão-Mor Manuel Domingues Salgueiro, os quais a história de Lorena registra como sendo os primeiros povoadores da região conhecida pelos bandeirantes, desde 1646, como o "Pôrto de Guaypacaré da Freguesia de N. S. da Piedade."

Aprendeu as primeiras letras na escola pública dos conhecidos educadores Adolfo Rios e sua mulher Inês de Aquino Rios.

Depois, em 1917, ainda em Lorena, ingressou no Ginásio de São Joaquim, dos padres salesianos, onde se bacharelou em Ciências e Letras, no ano de 1922.

Logo, em seguida, foi para São Paulo, matriculando-se, simultâneamente, na Faculdade de Filosofia, Ciências e Letras de São Bento, quando agregada à Universidade de Louvain, e na Faculdade de Direito do Largo de São Francisco. 
Bacharelou-se em Filosofia, Ciências e Letras em 1926, e, dois anos após, em 1928, tira o seu diploma de bacharel em Ciências Jurídicas e Sociais pela nossa tradicional Academia de Direito. Aí, fêz brilhantíssimo curso, destacando-se como o Primeiro aluno de sua turma, sendo, então, laureado, por decisão unânime da Congregação, com o "Prêmio Rodrigues Alves"

Após a formatura, foi atraído pela política, participando das lutas cívicas do Partido Democrático. Depois da revolução de 1932, exilados os seus diretores, assumiu a Secretaria Geral do Partido, que passou a ser presidido pelo Prof. J. J. Cardozo de Melo Neto, em substituição ao Prof. Francisco Morato, o Chefe civil do movimento.

Convocada a Constituinte de 1934, foi um dos quatro Diretores do pleito da "Chapa Única por São Paulo Unido", como representante da agremiação de cuja Secretaria Geral fôra o dinâmico titular, na fase crítica que sucedeu à derrota militar do povo paulista.

Foi, ainda, um dos fundadores do Partido Coństitucionalista, presidido por Armando Sales de Oliveira, sob cuja legenda foi eleito deputado à Assembléia Constituinte de São Paulo, no ano de 1934.

Com o golpe de 1937, abandonou as atividades políticas, voltando a se dedicar, integralmente, à vida intelectual. Faz o curso de Doutorado na mesma Escola onde, antes, se bacharelara, e, ainda em São Paulo, cursa a seção de Ciências Sociais e Políticas da Faculdade de Filosofia, Ciências e Letras da nossa Universidade, onde é aluno dos grandes economistas franceses François Ferroux, René Courtin e Pierre Fromont, da Faculdade de Direito da Universidade de París.

Logo depois, em 1941, vai para Minas Gerais disputar a Cátedra de Direito Industrial e Legislação do Trabalho na tradicional Casa de Afonso Pena. Vence, em brilhantíssimas provas, quatro notáveis concorrentes e é nomeado titular da Cadeira que exerce até julho de 1956. 
Neste ínterim, conquista a Livre-docência de Direito Constitucional na Faculdade Nacional de Direito da Universidade do Brasil Depois, concorre com o Ministro Cândido Mota Filho à cadeira de Direito Constitucional na Faculdade de Direito de São Paulo, classificando-se em segundo lugar, com dois votos para a cátedra e um décimo a menos nas notas finais, em relação ao primeiro classificado.

Volta à Minas Gerais, onde continua a sua atividade didática que foi, sempre, muito intensa. De fato, além de duas cátedras, ocupou, interinamente, a Cadeira de Economia Política, no Curso de Bacharelado, de 1945 a 1951. Foi, ainda, titular da Cátedra de Economia Social e Legislação do Trabalho, no Curso de Doutorado, desde o ano letivo de 1951.

E, em sua terra natal, foi um dos fundadores da Faculdade Salesiana de Filosofia, Ciências e Letras, onde é titular da Cadeira de Psicologia Racional, da seção de Filosofia, tendo lecionado, também, Sociologia Geral, no Departamento Feminino da mesma Faculdade.

É membro correspondente do Instituto Histórico e Geográfico da Bahia, do Instituto da Ordem dos Advogados de Minas Gerais, do Instituto de Direito Social de São Paulo e de outras instituições culturais.

Além da tese com que conquistou a Cátedra de Economia Política na nossa Faculdade e intitulada "A Produção sob o Regime da Emprêsa", o Professor Pinto Antunes é autor das seguintes obras, versando os mais variados assuntos jurídicos e sociais:

Raciocracia - Forma Científica de Govêrno - São Paulo, 1933.

A Filosofia do Estado Moderno - São Paulo - 1934.

A Filosofia da Ordem Nova - A Questão Social e a sua Solução — Rio de Janeiro - 1938. 


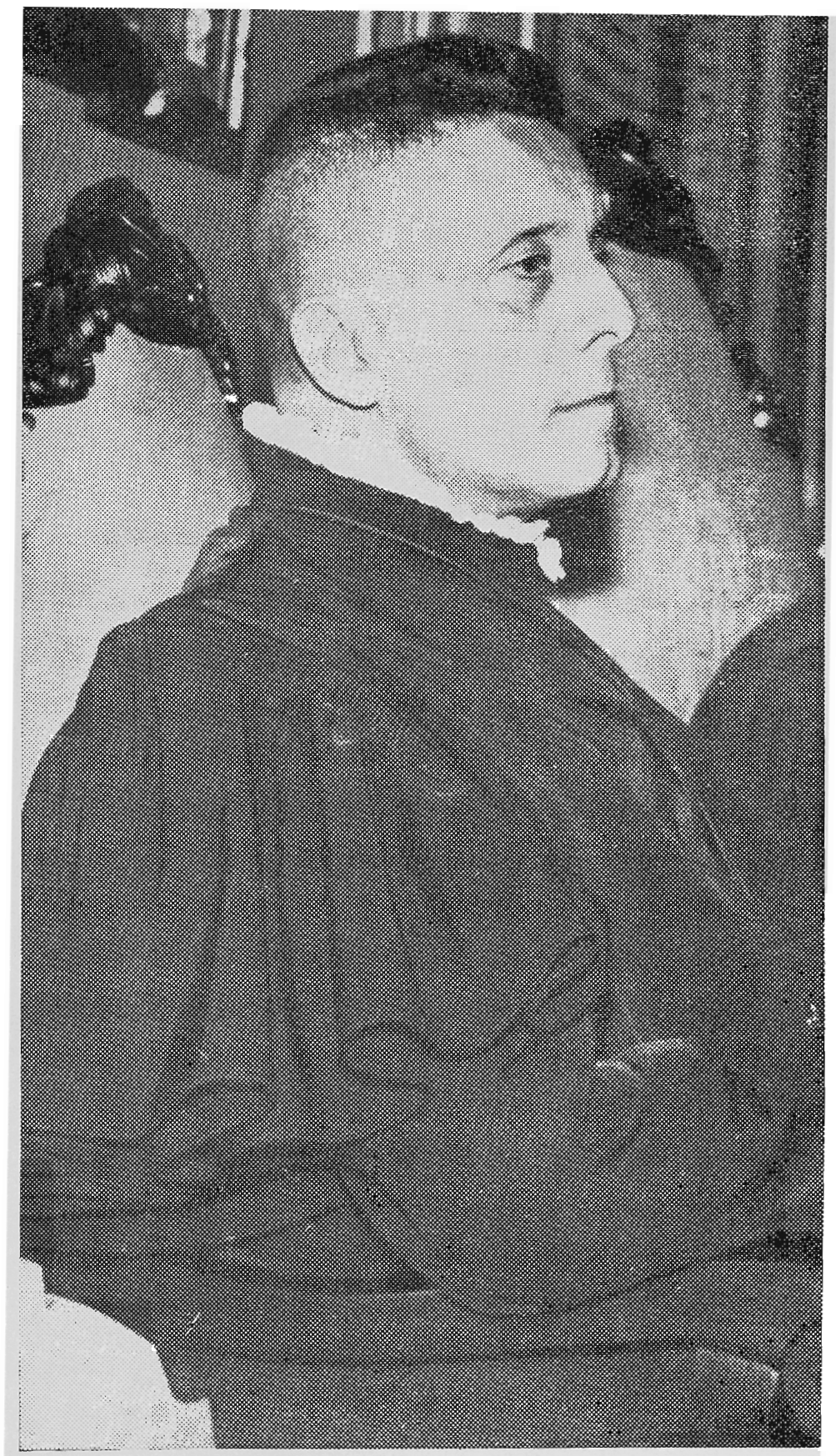

Prof. José Pinto Antunes, ncvo catedrático de Economia Política. 
Do Sindicato Operário. Apogeu e decadência - São Paulo, 1939.

Da concorrência desleal na Legislação Brasileira Sinópse do Direito Industrial — São Paulo, 1940.

O Direito da Emprêsa - Preleções resumidas e mimeografadas (sob a responsabilidade da cadeira) do curso de Direito Industrial e Legislação do Trabalho, professado na Faculdade de Direito da Universidade de Minas Gerais (2 Vols.), 1942.

Introdução Econômica ao Estudo do Direito - Idem, do Curso de Economia Política (1 vol.), 1946.

Os Direitos do Homem no Regime Capitalista - São Paulo, 1947.

Da Limitação dos Poderes - São Paulo, 1950.

Artigos e Pareceres:

Impõe-se a Unificação Jurídico-Mercantil Universal anteriormente da Unificação do Direito Privado - "Revista dos Tribunais", São Paulo, vol. 60, 1926.

No Direito Sírio, não há Direito de Representação; outrossim, os irmãos germanos excluem os consanguineos da vocação hereditária - "Pandectas Brasileiras", Rio de Janeiro, vol. 5, 1928.

Álvares de Azevedo, o romântico da inteligência - "Revista da Faculdade de Direito de São Paulo", vol. 27, 1931.

Há questão Social no Brasil? - Revista "XI de Agôsto", São Paulo, 1934.

Discursos e Pareceres — Anais de 1935-7 da Assembléia Legislativa de São Paulo.

O Direito ao Emprêgo - "Revista do Trabalho", Rio de Janeiro, 1941, pp. 563 e segs.

Pressupostos Econômicos das Definições de Direito Industrial e Legislação do Trabalho - "Revista do Trabalho", Rio de Janeiro, 1941, pp. 507 e segs. 
A Concepção do Direito Insdustrial e Legislação do Trabalho - "Revista Forense", Rio de Janeiro, vol. 88, pp. 331 e segs., 1941.

Generalidades sobre o Contrato de Trabalho -- "Revista do Trabalho", Rio de Janeiro, 1942, pp. 477 e segs.

o Nome Comercial, Homonímia, Pseudonímia. A Insigna - "Revista Forense", Rio de Janeiro, vol. 91, pp. 347 e segs., 1942.

O Direito da Emprêsa - "Trabalho e Seguro Social", Rio de Janeiro, Vol. 3, nos 1, 2 e 3, 1943.

A Legislação do Trabalho é uma auto-disciplina do Capitalismo - "Legislação do Trabalho", São Paulo, vol. 7, n. ${ }^{0} 73$, pp. 167 e segs., 1943.

O Salário, preço da subordinação. As Gratificações. Outros Complementos — "Revista de Direito Social", São Paulo, vol. 4, n. ${ }^{\circ}$ 18, pp. 35 e segs., 1943. "Direito", Rio de Janeiro, vol. 22, pp. 121 e segs., 1943.

$O$ Gerente e a Legislação Trabalhista. O Contrato Misto. "Revista do Trabalho", Rio de Janeiro, pp. 283 e segs.

Transferências de Lugar e Funções - "Revista do Trabalho", Rio de Janeiro, 1943, pp. 141 e segs.

Concorrência Desleal na Legislação Brasileira -- "Revista do Trabalho", Rio de Janeiro, 1943, pp. 141 e segs.

Apogeu e Decadência do Sindicato Operário - "Revista Forense", Rio de Janeiro, vol. 95, pp. 34 e segs., 1943.

O Salário, na Consolidação das Leis do Trabalho "Revista Forense", Rio de Janeiro, vol. 96, pp. 579 e segs., 1943.

A Falta Grave e a Fôrca Maior - "Boletim do Ministério do Trabalho, Indústria e Comércio", Rio de Janeiro, n. ${ }^{\circ} 115$, pp. 70 e segs., 1944. 
Salário, Participação nos Lucros e Gratificações "Revista Forense", Rio de Janeiro, vol. 96, pp. 579 e segs., 1943.

Auxiliares do Comércio - "Revista do Trabalho", Rio de Janeiro, 1944, pp. 369 e segs.

Gratificações condicionadas ao lucro da Emprêsa. Ato de Liberalidade do Empregador - "Revista do Trabalho", Rio de Janeiro, 1944, pp. 369 e segs.

O Salário Equitativo. Uma Inovação da Consolidação das Leis do Trabalho - "Minas Jurídica", Belo Horizonte, vol. $1, \mathrm{n}^{\circ}$ 1, pp. 9 e segs., 1944.

Renùncia à Estabilidade - "Minas Jurídica", Belo Horizonte, Vol. 1, n. ${ }^{\circ}$ 3, pp. 271 e segs., 1944.

El Problema de la Subordinación en el Contrato individual del Trabajo - "Derecho del Trabajo", Buenos Ayres, n. ${ }^{\circ} 3$, pp. 115 e segs., 1944.

A Participação dos Operários nos Lucros da Empresas — "Digesto Econômico", São Paulo, n. ${ }^{\circ} 22$, pp. 48 e segs., 1946.

Contrato Coletivo do Trabalho. Acôrdo entre Banqueiros e Bancários — "Revista Forense", Rio de Janeiro, Vol. 107, pp. 247 e segs., 1946.

Alterações contratuais por Atos Administrativos -"Revista do Trabalho", Rio de Janeiro, 1946, pp. 11 e segs.

Da Concorrência Pública - "O Estado de Minas", Belo Horizonte, 26 de Novembro de 1946.

Do partido Político - Revista da Faculdade de Direito da Universidade de Minas Gerais, Belo Horizonte, outubro de 1952.

A Interpretação Econômico-Jurídica da Constituição "Revista Forense", Rio de Janeiro, vol. 143, fasciculos 591-2, pp. 21, 1953. 
Foi com tal bagagem intelectual, constituída daqueles títulos e com estas obras, atestando uma vida inteira de dedicação aos estudos das Ciências Sociais, que o Professor José Pinto Antunes disputou com seis fortes concorrentes e venceu com galhardia a Cátedra de Economia Política da Faculdade de Direito da Universidade de São Paulo, na qual, em sessão solene da Congregação, foi empossado no dia 9 de agôsto de 1956, pronunciando, então, as seguintes palavras, em resposta à saudação que lhe fizera, em nome da Congregação, o Prof essor Gofredo da Silva Teles Júnior:

Meu eminente Dỉretor e querido amigo Professor e Doutor Alvino Lima.

Douta Congregação.

Confesso-me gratìssimo a todos pela honrosa presença no ato solene pelo qual assumo a dignidade máxima que, desde os meus tempos acadêmicos, constitui a minha ambição maior e suficiente - ser Professor da Faculdade de Direito de S. Paulo.

Tal como Jacó eu também amava doidamente esta "serrana bela.

"Porém o pai, usando de cautela

Em lugar de Raquel lhe dava Lia.

Vendo o triste pastor que com enganos

Lhe fora assim negada a sua pastora

Como se não tivera merecida

Comeca de servir outros sete anos,

Dizendo: Mais servira, se não fôra

Para tão longo amor tão curta a vida!"

\section{Senhores Professôres,}

Como requinte da cortesia e agravamento da emoção designaram VV. Excias., para me dizer as palavras de estilo, a êste amigo de truz que é o eminente Professor Doutor Gofredo da Silva Teles Júnior "meu velho e querido amigo"; sim, "meu velho e querido amigo", tal como me chamou 
quando rigoroso examinador, porque é uma amizade que cultívo há três gerações. Fui amigo da saudosa Dama paulista a Exma. Senhora sua avó - D. Olívia Guedes Penteado. Distingue-me, em continuação, com a sua honrosa amizade, o casal Gofredo Teles. Assim, também, o neto e o filho de velhos amigos meus é e devera ser mesmo "meu velho e querido amigo". Por isso tudo é que são suspeitos, por amizade íntima, os elogios que acabo de receber e os "contesto por negação geral.

Não devo aos meus pares um programa de compromisso porque vou simplesmente continuar nesta casa a dignificante função de ensinar, que iniciei há 15 anos precisamente, na minha querida Faculdade de Direito da Universidade de Minas Gerais. Não mudarei em nada, porque em nada tenho que mudar.

Ensinei sempre os mesmos princípios - os da filosofia da dignidade do homem e as conseqüentes aplicações na ordem econômica e jurídica. A liberdade é o meu culto constante. Creio nela firmemente como fôrça criadora e até disciplinadora. A liberdade é o princípio de ordem na Economia e no Direito.

A ordem cristã, e eu sou Cristão da Igreja Católica, a Ordem Cristã, dí-lo, com a Sabedoria, Pio XII, "é, essencialmente, uma ordem de liberdade". A liberdade, acrescentamos, consiste na adesão a uma ordem.

A Economia, cujo conhecimento venho transmitindo aos meus alunos, está sempre ao serviço do Direito porque em função de um ideal de Justiça. Não obedece, pois, a demonstrações matemáticas, mas às imposições de uma vida social com dignidade. Interpreta a realidade para servir de guia à política do bem comum.

Não é, assim, uma ciência indiferente à sorte da pessoa humana. E', como o Direito, uma variedade da técnica de realização da paz consentida, característico fundamental dos regimes democráticos. Não é o saber pelo saber, mas o saber para servir ao homem no caminho do seu grande Destino. 
Foi sempre assim que ensinei e hoje, na Universidade de Minas Gerais, discípulos meus, muito superiores ao Mestre, nas cátedras que ocupam, difundem a mesma doutrina, formando as novas gerações para o serviço eficiente do progresso econômico e moral do Brasil.

De minha parte, meus Senhores, devo agradecer, ainda, e especialmente, ao Emérito Professor desta Casa - o Doutor José Joaquim Cardoso de Melo Neto, meu eminente Mestre e meu grande amigo, também o meu antecessor na Cátedra, de que hoje tomo a posse, o melhor do que sei e ensino. Aliás, nós todos, Mestres e alunos, tiramos o cortôrno e a fôrça do Ideal que nos anima, do rico acervo desta Faculdade, a grande mestra do serviço constante pela Pátria comum. Dela, das suas tradições e grandezas, somos todos, e simplesmente, os arautos, com maior ou menor brilho e eficiência.

Antes de terminar estas palavras de circunstância peço permissão a VV Excias. para voltar a minha lembrança e dirigí-la à Universidade de Minas Gerais, e especialmente, ao corpo docente e discente da Nobre Casa de Afonso Pena, com a saudação mais afetuosa e agradecida pela honra com a qual me acolheram entre os seus grandes Mestres e no seio da sua radiosa e encantadora mocidade.

Ao amorável povo mineiro dou a certeza do reconhecimento, por tôda a minha vida, pelo afeto com que sempre cercou a minha pessoa, suavizando com a bondade da compreensão humana a cruel nostalgia de quem padecia a saudade da família e da terra natal distante.

\section{Meus Senhores.}

Afinal, tudo acabou.

Durante 15 anos, com o poeta máximo dos mineiros, eu também cantava e descantava. 
"No meio do caminho tinha uma pedra tinha uma pedra no meio do caminho tinha uma pedra no meio do caminho tinha uma pedra.

Nunca me esquecerei dêsse acontecimento na vida de minhas retinas tão fatigadas.

Nunca me esquecerei que no meio do caminho tinha uma pedra tinha uma pedra tinha uma pedra no meio do caminho no meio do caminho tinha uma pedra."

Afinal, tudo acabou. No meio do caminho não existe mais a pedra do poeta. Dos obstáculos eu fiz a maior vitória da minha vontade teimosa.

Tudo acabou e ainda com Carlos Drumond de Andrade eu continuo a cantar entre satisfeito e desolado:

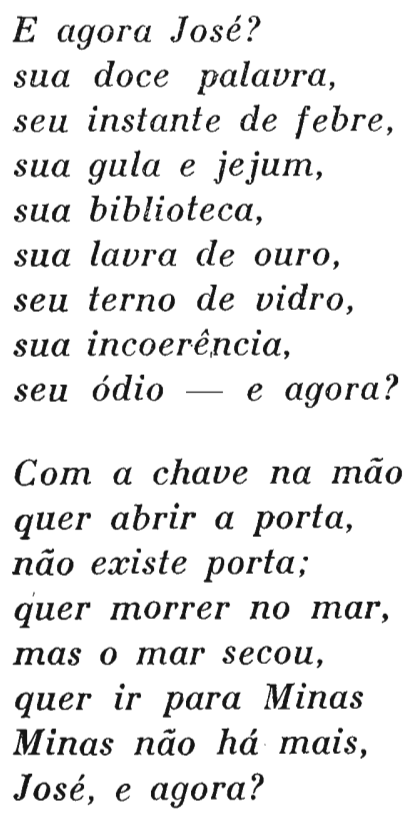




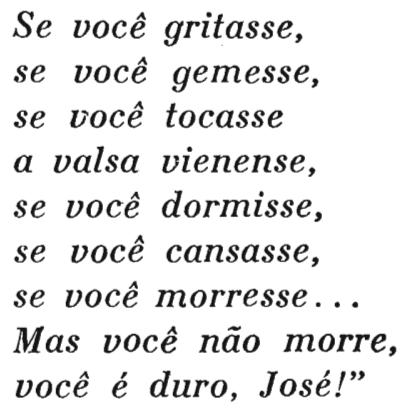

Meus Senhores.

Entro nesta Casa e volto a São Paulo com a mais profunda emoção. E peço a Deus com fervor que me conceda outra graça - a da modéstia, para viver sem orgulho a grande mercê de ser Paulista no Brasil e Professor de Direito na Faculdade de Direito do Largo de São Francisco.

Meu Diretor. Senhores Professôres. Meus Amigos. A todos, o meu mais profundo e afetuoso reconhecimento pelas homenagens que acabo de receber. 